Drozd Małgorzata, Czarnota Jakub, Dobrzyński Michał, Skubel Tomasz, Sokół Dorota, Dudek Iga, Piecewicz-Szczęsna Halina. Impact of oral isotretinoin therapy on musculoskeletal system and physical activity in patients with acne. Journal of Education, Health and Sport. 2020;10(8):372-382. eISSN 2391-8306. DOI http://dx.doi.org/10.12775/JEHS.2020.10.08.045

https://apcz.umk.pl/czasopisma/index.php/JEHS/article/view/JEHS.2020.10.08.045

https://zenodo.org/record/4001121

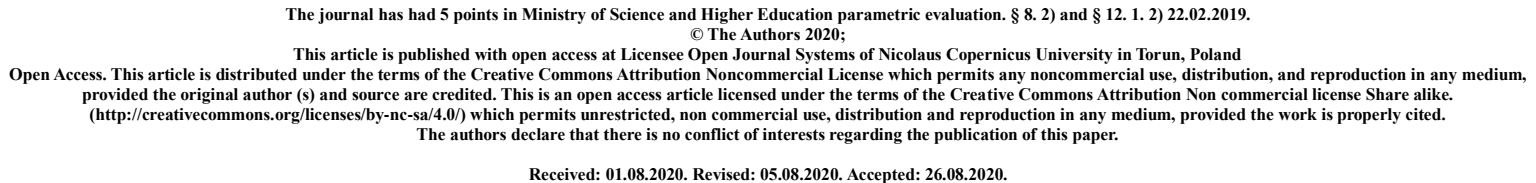

\title{
Impact of oral isotretinoin therapy on musculoskeletal system and physical activity in patients with acne
}

\author{
Małgorzata Drozd $^{1,}$ Jakub Czarnota $^{1}$, Michał Dobrzyński ${ }^{1}$, Tomasz Skubel ${ }^{1}$, \\ Dorota Sokól ${ }^{1}$, Iga Dudek ${ }^{1}$, Halina Piecewicz-Szczęsna ${ }^{2}$ \\ ${ }^{1}$ Student Research Circle at the Department of Epidemiology and Clinical Research \\ Methodology, Medical University of Lublin \\ ${ }^{2}$ Department of Epidemiology and Clinical Research Methodology, Medical University of \\ Lublin \\ Corresponding author: Halina Piecewicz-Szczęsna, e-mail: halpiec@wp.pl \\ ORCID ID: \\ Małgorzata Drozd: https://orcid.org/0000-0002-0710-2451; drozd.malg@ gmail.com \\ Jakub Czarnota: https://orcid.org/0000-0003-2783-0349; kubbaa232@interia.pl \\ Michał Dobrzyński: https://orcid.org/0000-0002-1416-6568; mdobrzyski4@gmail.com \\ Tomasz Skubel: https://orcid.org/0000-0001-7572-401X; \\ tomasz.wojciech.skubel@gmail.com \\ Dorota Sokół: https://orcid.org/0000-0003-2059-7951; dorota.soko19606@gmail.com \\ Iga Dudek: https://orcid.org/0000-0002-8101-074X; iga.dudek6@gmail.com \\ Halina Piecewicz-Szczęsna https://orcid.org/0000-0002-0573-7226; halpiec@wp.pl
}




\begin{abstract}
Introduction and purpose: Isotretinoin, the vitamin A derivative, has been commonly used in treatment of acne vulgaris for years. Despite its unquestionable efficacy, chronic oral isotretinoin treatment leads to multiple side effects. The aim of study is analysis of musculoskeletal symptoms prevalence during oral isotretinoin treatment and their impact on physical activity.

Material and methods: The study was conducted using the original survey questionnaire shared online among members of Polish group of patients treated for acne. Total of 196 responses were analyzed and compared with up-to-date literature related to the topic.

Results: $86,7 \%$ of respondents reported at least one of the musculoskeletal symptoms. The most common were back pain $(82,7 \%)$, fatigue and lethargy $(70,4 \%)$, myalgia $(55,1 \%)$ and arthralgia (32,1\%). In 97,6\% cases adverse effects were developed within the first 6 months of treatment. In 64,2\% they persisted during the whole therapy, sometimes even beyond. Due to musculoskeletal side effects, in $2,4 \%$ cases dose reduction was necessary, $1,8 \%$ of respondents had to stop treatment and $48 \%$ had to limit or stop physical activity. $71,4 \%$ of respondents reported that lower back pain occurred or escalated during isotretinoin treatment.

Conclusions: Prevalence of reported musculoskeletal symptoms is very high and totals $86,7 \%$. They result in prolonged limiting or stopping of physical activity in almost $50 \%$ of people. Although musculoskeletal symptoms are typically benign, possibility of severe disorders and potential permanent effects must be taken into consideration.
\end{abstract}

Key words: acne, isotretinoin, adverse effects, physical activity, musculoskeletal disorders

\title{
Introduction:
}

Acne vulgaris is the most common skin disease. In the European countries the overall adjusted prevalence of self-reported acne amounts up to $57.8 \%$, the highest rate occurs in youth 15 to 17 years old and decreases with age [1]. This disease may affect more than $80 \%$ of teenagers. Acne, as non-inflammatory lesions (open and closed comedones) or inflammatory lesions (papules, pustules or nodules) mostly appears on the face, sometimes on the torso [2,3]. Acne vulgaris is a chronic condition that has strong impact on the quality of life. It causes low self-esteem associated with psychosocial burden and anxiety. Nevertheless, quality of life usually improves after successful treatment [4].

Isotretinoin is the vitamin A-derivative the cis-isomer of retinoic acid. It is converted in vivo to all-trans retinoic acid, which induces cellular effects via binding to nuclear acid receptors, retinoid X receptors (RXRs), and retinoid acid receptors (RARs) [5]. Recent studies report that retinoids have influence on cellular growth, differentiation, morphogenesis and apoptosis, they inhibit tumour promotion and malignant cell growth, exert immunomodulatory actions and alter cellular cohesiveness. Therefore, not only acne and rosacea can be treated with isotretinoin, but also some of inflammatory and malignant disorders [6].

Isotretinoin has remained the single most effective anti-acne therapy, since when it was introduced to the market by Hoffman-La Roche in 1982 [7]. It provides significant improvement in many patients and long-term remission [8-10]. It is the only therapy that affects all major etiological factors of acne. 
Oral isotretinoin treatment results in a significant reduction in sebum production, comedogenesis, ceratinisation, has anti-inflammatory properties and indirectly lowers colonization with Propionibacterium acnes [9]. The indication for oral isotretinoin treatment is acne that does not respond to other treatment or acne that causes psychological problem as separate indication [11].

Despite isotretinoin's unquestionable efficacy, chronic oral isotretinoin treatment leads to multiple adverse effects. The highest prevalence of adverse effects were observed in patients that were treated with the highest doses [8]. The most common and well known problems are mucocutaneous, ocular, psychiatric, gastrointestinal side effects, as well as teratogenicity. Surprisingly, little attention has been paid to the potential musculoskeletal side effects of retinoids [5,12]. Myalgia, tiredness and arthralgia are one of the most frequently reported symptoms during isotretinoin therapy [11].

\section{Aim:}

The aim of this study is analysis of musculoskeletal symptoms among patients treated with isotretinoin for dermatological disorders, especially acne vulgaris and their impact on physical activity.

\section{Materials and method:}

The study was conducted in July 2020 using the original survey questionnaire, addressed to members of Polish group of patients treated for acne. Participation in the study was anonymous and voluntary. Participating members completed an online questionnaire that included questions about symptoms, especially musculoskeletal, which they observed during their anti-acne isotretinoin treatment and 1 month after its termination. They were also questioned about features of pain and its influence on their physical activity. Data was analysed and compared with current PubMed publications.

\section{Results:}

A total of 196 answers were collected. The study involved 185 females $(94,4 \%)$ and 11 males $(5,6 \%)$ in age 13-41. The average age was 21,43, with a median of 21 and the standard deviation was 4,74 . The causes of isotretinoin treatment were acne vulgaris $(92 \%)$, acne fulminans (3\%), acne keloidea $(1,6 \%)$ and other types $(3 \%)$ : acne inversa/hydradenitis suppurativa -2 , seborrheic dermatitis -2 , hormonal acne -2 , acne rosacea -1 . Reported daily isotretinoin dose range varied between $0,13-1,11 \mathrm{mg} / \mathrm{kg} /$ day (mean $0,54 \mathrm{mg} / \mathrm{kg} /$ day).

86,7\% (170 out of 196 patients) provided an affirmative answer to the question if they experienced fatigue, lethargy, muscle pain, joint pain or stiffness. Lower back pain was reported by $-82,7 \%$ (162), fatigue and lethargy 70,4\% (138), nonspecific back pain $-66,3 \%$ (130), myalgias - 55,1\% (108), arthalgias - 32,1\% (63), stiffness of muscle and joints $26,0 \%$ (51), spine pain in the cervical and thoracic region - 25\% (49), limb pain - 25\% (49), heel pain - 16,3\% (32) - table 1. Other, less frequently reported musculoskeletal symptoms were knee pain $-1 \%$ (2) and sternum and shoulders pain $-1 \%$ (2). 


\begin{tabular}{|l|l|}
\hline Symptom & $\begin{array}{l}\text { Patient group (no. \%) } \\
\text { total no. 196 }\end{array}$ \\
\hline Lower back pain & $162(82,7 \%)$ \\
\hline Fatigue and lethargy & $138(70,4 \%)$ \\
\hline Back pain & $130(66,3 \%)$ \\
\hline Myalgia & $108(55,1 \%)$ \\
\hline Arthralgia & $63(32,1 \%)$ \\
\hline Stiffness of muscle and joints & $51(26,0 \%)$ \\
\hline Spine pain in the cervical and thoracic region & $49(25,0 \%)$ \\
\hline Limb pain & $49(25,0 \%)$ \\
\hline Heel pain & $32(16,3 \%)$ \\
\hline
\end{tabular}

Table 1 . The most common musculoskeletal findings and proportions.

These symptoms mostly developed in the first 6 months of therapy. 32,9\% of respondents claim that they occurred in less than 1 month after starting the isotretinoin treatment, $64,7 \%$ - between $2^{\text {nd }}$ and $6^{\text {th }}$ month, $1,2 \%$ - between $7^{\text {th }}$ and $12^{\text {th }}$ month, $0,6 \%$ - over 12 months after and 0,6\% - within 1 month after the end if therapy (Figure 1). 48,8\% of those who had musculoskeletal symptoms say that they persisted with variable intensity throughout the whole therapy. 15,4\% experienced them during and over one month after termination of treatment. $13.6 \%$ had side effects, mentioned above, for more than one month, but less than time of entire therapy. In $11 \%$ of people they lasted short time, less than 7 days and in $11 \%$ - between 7 days and 1 month (Figure 2).

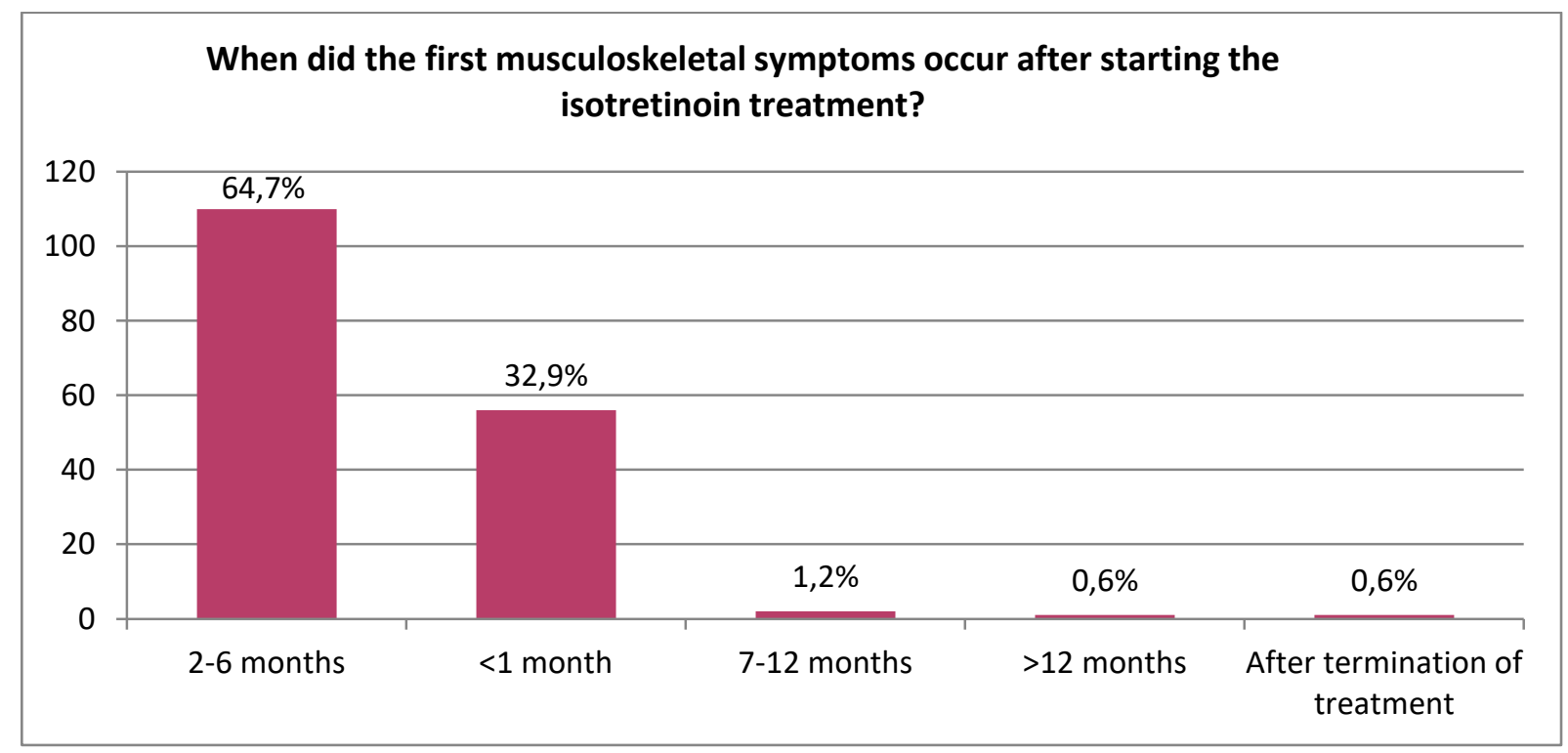

Figure 1. Time to onset of musculoskeletal symptoms in respondents. 


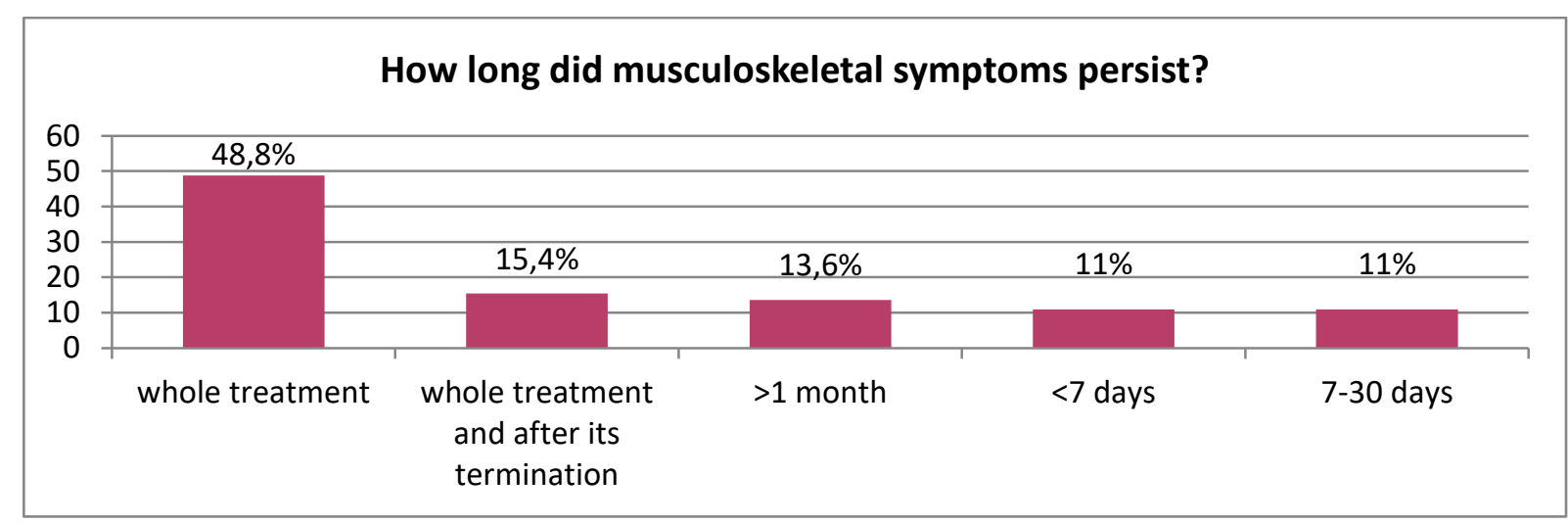

Figure 2. Duration of musculoskeletal symptoms reported by respondents.

In $95,3 \%$ (161) of people who experienced muscle symptoms (170) there was no need to stop treatment. In 2,4\% (4) dose reduction was necessary and 1,8\% (3) had to stop treatment due to musculoskeletal side effects of isotretinoin.

$48 \%$ (94) off all respondents (196) had to limit or stop physical activity due to musculoskeletal symptoms during treatment. In the questionnaire physical activity was defined as 150 minutes of physical activity per week or doing manual work for 8 hours daily. $61,7 \%$ (121) considered themselves as physically active people, and 38,3\% (75) as not. Among people physically active $47 \%$ (57/121) had to limit or stop physical activity because of musculoskeletal symptoms during treatment. Among people not physically active 49\% (37/75) had to limit or stop physical activity.

CK levels were elevated in $6,1 \%$ of patients (12), remained within normal range in $39,8 \%$ (78) and were unknown in 54,1\% (106). Among people physically active CK levels were elevated in 5,8\% (7), normal in 43,0\% (52) and unknown in 51,2\% (62). Among people who are not physically active CK levels were elevated in 6,7\% (5), normal in 34,7\% (26) and unknown in 58,7\% (44). Among people with musculoskeletal symptoms active CK levels were elevated in 5,9\% (10), normal in 38,2\% (65) and unknown in 55,9\% (95). Among people without any musculoskeletal symptoms active CK levels were elevated in 7,7\% (2), normal in $50 \%$ (13) and unknown in 42,3 (11).

Respondents were asked about lower back pain in detail. 82,7\% (162) claimed that they experienced lower back pain during treatment. 44,9\% (88) claimed that it occurred for the first time after starting isotretinoin treatment. 26,5\% (52) said that pain had occurred before starting treatment and escalated during it.11,2\% (22) suffered from lower back pain which remained the same during therapy. 14,8\% (29) did not have lower back pain and 2,6\% (5) did not remember if they had (Figure 3). 


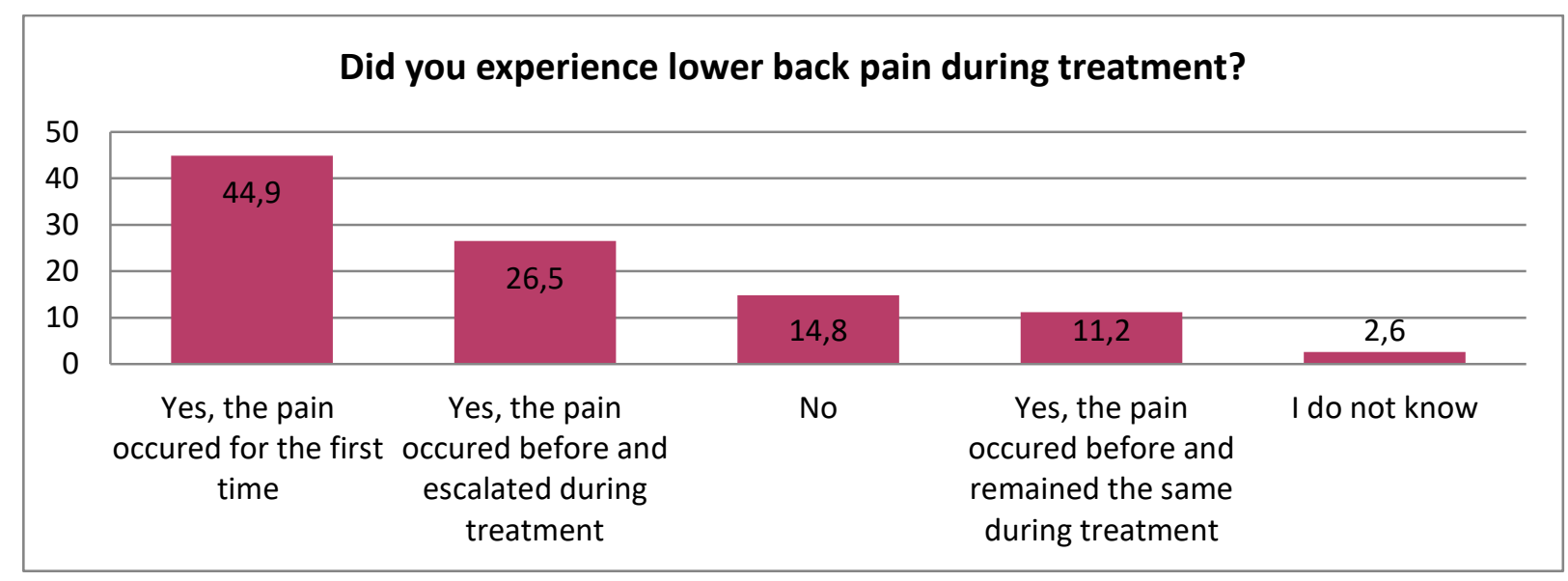

Figure 3. Prevalence of lower back pain during isotretinoin treatment among respondents.

Among those who answered the question about features of lower back pain affirmatively (162): In 56,8\% of people (92) physical activity did not lessen the lower back pain, in $13,6 \%$ (22) physical exercises reduced pain and 29,6\% (48) did not know. In 53,1\% (86) rest brought pain relief, in $39,5 \%$ there was no relief with rest, $7,4 \%$ (12) did not know. Lower back pain appeared at night and improved with rising in $24,7 \%$ (40). There was no nocturnal pain in $65,4 \%$ (106) and 9,9\% (16) did not know (Table 2).

$67(41,4 \%)$ respondents reported one of the features of inflammatory lower back pain, 26 $(16,0 \%)$ - two features and $2(1,25 \%)$ - all three features, pain relieved with exercise, did not relieve with rest and occurred at night.

\begin{tabular}{|c|c|c|c|}
\hline $\begin{array}{lr}\text { Feature } & \text { of } \\
\text { inflammatory } & \text { lower } \\
\text { back pain } & \end{array}$ & Yes & No & I don't know \\
\hline Relief with exercise & $13,6 \%$ & $56,8 \%$ & $29,6 \%$ \\
\hline No relief with rest & $39,5 \%$ & $53,1 \%$ & $7,4 \%$ \\
\hline $\begin{array}{l}\text { Nocturnal pain } \\
\text { (improving with rising) }\end{array}$ & $24,7 \%$ & $65,4 \%$ & $9,9 \%$ \\
\hline
\end{tabular}

Table 2. Inflammatory features of pain among patients with lower back pain.

\section{Discussion:}

Musculoskeletal and mucocutaneous symptoms are the most common side effects of isotretinoin treatment. According to the one of the large retrospective reviews, myalgia occurs in $39 \%$ of patients, tiredness in $18 \%$ and arthralgia in $12 \%$ [11]. Results of our study point out even higher frequency of musculoskeletal side effects, despite the fact that all of the respondents were treated with low doses of isotretinoin. Lethargy was reported more often $(70,4 \%)$ than in another clinical study, conducted on the group of 73 patients with acne vulgaris, where it was found in $50,7 \%$. Similarly, lower back pain was reported in $82,7 \%$ vs. $49,3 \%$ and myalgia $-55,1 \%$ vs. $42,5 \%$ [13]. The other symptoms, listed with substantial frequency, were arthralgia, nonspecific back pain, spine pain in cervical and thoracic region, limb pain and heel pain. 
Almost all of the respondents reported that musculoskeletal symptoms appeared within first 6 months of treatment, out of which 33\% started on the first month of therapy and $65 \%$ between $2^{\text {nd }}$ and $6^{\text {th }}$ month. Still, in $2 \%$ of respondents, symptoms occurred later or even after termination of the treatment. They can result in limiting physical activity for the long time. Almost $50 \%$ of respondents say that adverse effects persisted with variable intensity throughout the whole therapy, which usually lasts for months [6]. Moreover, 15,4\% experienced them even long time after termination of treatment. In $35,6 \%$ of responders, musculoskeletal symptoms lasted shorter, sometimes for less than one month or even less than 7 days.

Because of these side effects almost half of the patients had to limit or even stop any physical exercises. That information in addition to high frequency of musculoskeletal side events and their long persisting emphasizes the importance of this issue. A large amount of people during isotretinoin therapy may lose all of the benefits of physical activity by its limiting or stopping. Despite the unarguable positive impact on cardiovascular system, physical activity has favorable effect on bone and joints, such as increasing bone mineral density in femoral neck, slowing down the damage in small joints, improving of endothelial function and slowing of atherosclerotic process. It may also increase self-esteem and decrease pain perception. Resistance training decreases systemic inflammation and may have positive influence on isotretoin-induced spondyloarthropathies and other inflammatory side events [14]. In results of our study, there was slightly no difference between group physically active and inactive in frequency of limiting physical activity during isotretinoin therapy due to musculoskeletal symptoms.

Muscle symptoms may be associated with elevation of blood levels of creatine kinase(CK), a specific marker of muscle destruction. During isotretinoin treatment CK may be elevated occasionally up to 100 times the normal value, particularly in patients undergoing vigorous physical exercise, with or without any muscle symptoms. Hiper-CK-emia is a benign phenomenon, that may occur in $15-50 \%$ patients treated with isotretinoin. Nevertheless, measurement of $\mathrm{CK}$ levels as well as renal tests should be conducted in patients with musculoskeletal symptoms in order to detect possible rhabdomyolysis [15,16]. Acute rhabdomyolysis is the most severe muscle-related adverse effect, which left untreated can lead to acute renal failure [12]. In our study elevated level of creatine kinase occurred in total of $6,1 \%$ respondents, in $5,8 \%$ among people physically active and in $6,7 \%$ of those who are inactive. In patients with musculoskeletal symptoms elevated CK level occurred in 5,1\%, without them - in $7,0 \%$. However, in $54,1 \%$ of respondents CK level remained unknown, seriously limiting the analysis.

Elevation of CK levels may occur due to cytokine-mediated muscle damage during physical activity or viral infections in patients treated with isotretinoin. The other mechanism seen in vitro is rapid decreasing of mitochondrial membrane potential by isotretinoin, then releasing cytochrome c to the cytosol, which initiates the apoptosis, in similar way as in mitochondrial myopathies. CK levels may be also in normal range, despite clinical symptoms of myopathy [12]. Isotretinoin-induced myalgia may be related to TRAIL-mediated muscle cell apoptosis, although direct evidence is missing [7]. 
In patients with myalgia, weakness or elevated CK levels isotretinoin dosage should be reduced or temporarily discontinued. Moreover, those patients should avoid strenuous physical activity [15]. Elevated CK is not a contraindication for isotretinoin therapy [16].

In our study arthralgia were reported by $32,1 \%$ of respondents and stiffness of muscles and joints by $26 \%$. Arthralgia are typically mild and disappear when the treatment is stopped [17]. However, physicians should stay alert and look out for inflammatory features of pain. Arthalgias and stiffness of muscles and joints during isotretinoin treatment may be symptoms of rheumatologic side effects, such as bilateral and unilateral sacroiliitis, acute arthritis, enthesopathy, inflammatory lower back pain, polyneuropathy and myopathy [18]. They may be also symptoms of less frequent skeletal side effects - arthritis, skeletal and soft tissue calcification, premature epiphyseal closure, exostosis cartilaginea, periosteal proliferation, diffuse radiological bone hyperlucency [19].

In majority of our respondents musculoskeletal symptoms were localized in the back, especially in its lower regions, less frequently in cervical and thoracic region of the spine. They were also reported in the limbs, specifically in the heel, knee and sternum and shoulders. In lower back pain physicians should look out for sacroilitis, an inflammation occurring in the sacroiliac joint [13]. Spine pain may be a symptom of spondyloarthropathy and hyperostosis. Hyperostosis may be responsible for limitation of movement and localizes in cervical and thoracic spine. Enthesopathies might occur in the foot, pelvis, hip, shoulder and elbow. They are usually mild and asymptomatic [19]. Heel pain reported by $16,3 \%$ of our respondents may be associated with Achilles enthesopathy if the pain has inflammatory features [18].

Mono- or oligoarthritis are one of the less common isotretinoin's side effects. A few cases of true arthritis have been reported, the most frequently in the knee. Another significant side effect, sacroilitis, is an inflammation occurring in the sacroiliac joint and its association with isotretinoin has been recently well described [17]. Sacroilitis may also occur in patients with acne fulminans without isotretinoin treatment with $21 \%$ frequency and in SAPHO syndrome [20]. The mechanism by which isotretinoin leads to arthritis or sacroilitis is poorly understood, because retinoids foster the outgrowth and suppressive properties of regulatory $\mathrm{T}$ cells, which are likely to be protective mechanisms against spondyloarthropathy [18]. Isotretinoin may alter the structure of the liposomal membrane and sensitize the joint to degeneration with mild trauma. It may also increase MMP-2 activity, which is present at high levels in arthritic joints [17]. Isotretinoin-induced arthritis and sacroilitis are typically selflimiting and resolve within a few weeks or months after discontinuation of isotretinoin treatment and NSAIDs use [17,21]. However, they can lead to ankylosing and potentially permanent disability. For example, in one of the studies, indicating relation between sacroilitis and isotretinoin usage, 1 per 5 patients presented chronic sacroilitis in 1 year follow-up, despite discontinuation of isotretinoin treatment [21].

Lower back pain was reported with significant $82,7 \%$ frequency. $86,4 \%$ of those who reported lower back pain, claimed that the pain occurred for the first time during isotretinoin treatment or occurred also before, but escalated during treatment. Lower back pain may have inflammatory or mechanical features. In one prospective study inflammatory back pain occurred in $14,28 \%$ patients, while unlilateral sacroilitis appeared in 2,38\% [18]. Inflammatory lower back pain is one of the features of spondyloarthropathy and the main symptom of sacroilitis [22]. 
According to ASAS 2010 criteria, diagnosis of inflammatory back pain can be stated when minimum 4 out of 5 conditions are fulfilled: commencement under the age of 40 , insidious onset, relief with exercise, no relief with rest, nocturnal pain (improving with rising). In our study we asked all of respondents under 40 years old with lower back pain (160) about features of pain as a screening for inflammatory pain. 95 out of 160 respondents $(59,4 \%)$ had at least one of the inflammatory features of pain. Among that group only 2 respondents $(1,25 \%)$ confirmed the occurrence of all three features - pain relieved with exercise, did not relieve with rest and occurred at night (three inflammatory features). As a result they fulfilled ASAS criteria for inflammatory back pain (4/5 conditions) and should be diagnosed towards isotretinoin-induced spondyloartropathy with more objective methods, such as MRI in order to detect sacroilitis $[13,18]$. This analysis had limitations, for example insidious onset was difficult to assess. As a result, the prevalence of inflammatory low back pain was lower than in the one of the clinical studies, where it represented $44 \%$ of all patients with low back pain, while mechanical back pain - 66\% [13].

Rheumatologic disorders induced by isotretinoin, although commonly benign, can lead to permanent effects [23]. Destruction of cartilage and bone joints, as a consequence of ongoing inflammation in joints and hyperostosis may lead to disability [24]. Rheumatologic side effects can limit temporarily or even permanently patients' physical activity and as a result reduce its' positive influence on health.

There are number of limitations to this study. Respondents were members of the online group concentrating on isotretinoin treatment, so they may have joined it because of side effects and maybe they would have not searched for help online if they did not have any symptoms. As a result, the prevalence of side effects may be overstated. Moreover, there was no control group. Reported information were subjective and could not be verified with more objective methods. Nevertheless most of the side effects were reported in studies without such limitations. Musculoskeletal side effects of isotretinoin are widely discussed by patients online and considered to be a significant problem during therapy. This study may show the importance of the matter that remained ignored by clinicians.

\section{Conclusions:}

Prevalence of reported musculoskeletal symptoms is very high and totals $86,7 \%$. Majority of isotretinoin-induced musculoskeletal symptoms occurs early, within first 6 months of therapy and in most cases lasts for the entire therapy, resulting in prolonged limiting or stopping of physical activity in almost $50 \%$ of the people, with no difference between physically actveand inactive people. High prevalence of musculoskeletal symptoms, its long persisting and high frequency of limiting physical activity emphasize the importance of the issue. Elevated CK with or without musculoskeletal symptoms is an indication to avoid strenuous physical activity, but not a contraindication to isotretinoin therapy. Although musculoskeletal symptoms are typically benign, the possibility of severe disorders and potential permanent effects must be taken into consideration. The investigation of inflammatory pain, especially in lower back, and osteoarticular symptoms are necessary in order to avoid permanent disability due to rheumatologic diseases. 


\section{References:}

1. Wolkenstein P, Machovcová A, Szepietowski JC, Tennstedt D, Veraldi S, Delarue A. Acne prevalence and associations with lifestyle: a cross-sectional online survey of adolescents/young adults in 7 European countries. J Eur Acad Dermatol Venereol JEADV. 2018;32:298-306.

2. Costa CS, Bagatin E, Martimbianco ALC, da Silva EM, Lúcio MM, Magin P, et al. Oral isotretinoin for acne. Cochrane Database Syst Rev [Internet]. 2018 [cited 2020 Jul 22];2018. Available from: https://www.ncbi.nlm.nih.gov/pmc/articles/PMC6383843/

3. Katsambas AD, Stefanaki C, Cunliffe WJ. Guidelines for treating acne. Clin Dermatol. 2004;22:439-44.

4. Barnes LE, Levender MM, Fleischer AB, Feldman SR. Quality of life measures for acne patients. Dermatol Clin. 2012;30:293-300, ix.

5. Tan J, Boyal S, Desai K, Knezevic S. Oral Isotretinoin. Dermatol Clin. 2016;34:175-84. 6. Rademaker M. Isotretinoin: dose, duration and relapse. What does 30 years of usage tell us? Australas J Dermatol. 2013;54:157-62.

7. Melnik BC. Apoptosis May Explain the Pharmacological Mode of Action and Adverse Effects of Isotretinoin, Including Teratogenicity. Acta Derm Venereol. 2017;97:173-81. 8. Vallerand IA, Lewinson RT, Farris MS, Sibley CD, Ramien ML, Bulloch AGM, et al. Efficacy and adverse events of oral isotretinoin for acne: a systematic review. Br J Dermatol. 2018;178:76-85.

9. Layton A. The use of isotretinoin in acne. Dermatoendocrinol. Taylor \& Francis; 2009;1:162-9.

10. Borghi A, Mantovani L, Minghetti S, Giari S, Virgili A, Bettoli V. Low-cumulative dose isotretinoin treatment in mild-to-moderate acne: efficacy in achieving stable remission. $\mathrm{J}$ Eur Acad Dermatol Venereol JEADV. 2011;25:1094-8.

11. Brzezinski P, Borowska K, Chiriac A, Smigielski J. Adverse effects of isotretinoin: A large, retrospective review. Dermatol Ther. 2017;30:e12483.

12. Chroni E, Monastirli A, Tsambaos D. Neuromuscular adverse effects associated with systemic retinoid dermatotherapy: monitoring and treatment algorithm for clinicians. Drug Saf. 2010;33:25-34.

13. Baykal Selçuk L, Aksu Arıca D, Baykal Şahin H, Yaylı S, Bahadır S. The prevalence of sacroiliitis in patients with acne vulgaris using isotretinoin. Cutan Ocul Toxicol. 2017;36:176-9.

14. Verhoeven F, Tordi N, Prati C, Demougeot C, Mougin F, Wendling D. Physical activity in patients with rheumatoid arthritis. Joint Bone Spine. 2016;83:265-70.

15. Kaymak Y. Creatine phosphokinase values during isotretinoin treatment for acne. Int $\mathbf{J}$ Dermatol. 2008;47:398-401.

16. Marson JW, Baldwin HE. The creatine kinase conundrum: a reappraisal of the association of isotretinoin, creatine kinase, and rhabdomyolysis. Int J Dermatol. 2020;59:279-83.

17. Tasdelen OY, Yurdakul FG, Duran S, Bodur H. Isotretinoin-induced arthritis mimicking both rheumatoid arthritis and axial spondyloarthritis. Int J Rheum Dis. 2015;18:466-9. 18. Alkan S, Kayiran N, Zengin O, Kalem A, Kimyon G, Kilinc EO, et al. Isotretinoininduced Spondyloarthropathy-related Symptoms: A Prospective Study. J Rheumatol. The Journal of Rheumatology; 2015;42:2106-9. 
19. Kaplan G, Haettich B. Rheumatological symptoms due to retinoids. Baillieres Clin Rheumatol. 1991;5:77-97.

20. Barbareschi M, Paresce E, Chiaratti A, Ferla Lodigiani A, Clerici G, Greppi F. Unilateral sacroiliitis associated with systemic isotretinoin treatment. Int J Dermatol. 2010;49:331-3. 21. Aydog E, Ozturk G, Comert A, Tasdelen N, Akin O, Kulcu DG. Sacroiliitis during isotretinoin treatment: Causal association or coincidence? North Clin Istanb. 2018;6:75-80. 22. Zesztywniające zapalenie stawów kręgosłupa (ZZSK) [Internet]. [cited 2020 Jul 24]. Available from: http://www.mp.pl/social/chapter/B16.II.16.12.1.

23. Geller ASB, Alagia RFN. Sacroiliitis after use of oral isotretinoin - association with acne fulminans or adverse effect? An Bras Dermatol. 2013;88:193-6.

24. Schett G. Resolution of inflammation in arthritis. Semin Immunopathol. 2019;41:675-9. 